Chronic Obstructive Pulmonary Diseases:

Journal of the COPD Foundation

COPD

FOUNDATION

\title{
Review
}

\section{Physical Activity Monitoring in Patients with Chronic Obstructive Pulmonary Disease}

\author{
Shu-Yi Liao, MD, PhD, ${ }^{1}$ Roberto Benzo, MD, ${ }^{2}$ Andrew L. Ries, MD, $\mathrm{MPH}^{3}$ and Xavier Soler, MD, $\mathrm{PhD}^{3}$
}

\begin{abstract}
Reduced physical activity (PA) in patients with chronic obstructive pulmonary disease (COPD) is associated with increased morbidity and mortality (e.g. exacerbations) and eventually leads to disability, depression, and social and physical isolation. Measuring PA in this population is important to accurately characterize COPD and to help clinicians during a baseline evaluation and patient follow-up. Also, it may help increase adherence to PA programs. There are reliable objective and subjective methods available to measure PA. Recently, several new monitors have been developed that have improved accuracy of such measurements. Because these devices provide real-time feedback, they may help to improve participant self-motivation strategies and reinforce daily lifestyle modifications, one of the main goals in COPD management. This review focuses on describing available instruments to measure PA, specifically in patients with COPD. The reliability, validity, advantages, limitations, and clinical applications of questionnaires, pedometers, and accelerometers are discussed. Finally, based on current published literature, we propose recommendations about which methods may be most useful in different research or clinical settings.
\end{abstract}

\begin{abstract}
Abbreviations: physical activity, PA; World Health Organization,WHO; pulmonary rehabilitation, PR; Physical Activity Scale for the Elderly, PASE; the Zutphen Physical Activity questionnaires, ZPAQ; Stanford Seven-day Physical Activity Recall scale, PAR; International Physical Activity Questionnaire, IPAQ; Quantification de l'Activité Physique, QUANTAP; the COPD Exercise Study Questionnaire, COPDEX; vector magnitude unit, VMU; energy expenditure, EE; StepWatch Activity Monitor, SAM; pedometer, ped; uniaxial accelerometer, uni; triaxial accelerometer, tri; multisensory, multi

Funding Support: Not Applicable

Date of Acceptance: August 14, 2014

Citation: Liao S, Benzo R, Ries AL, Soler X. Physical activity monitoring in patients with chronic obstructive pulmonary disease. J COPD F. 2014;1(2): 155-165. doi: http://dx.doi.org/10.15326/jcopdf.1.2.2014.0131
\end{abstract}

1 School of Medicine, University of California-Riverside

2 Pulmonary and Critical Care Division, Mayo Clinic College of Medicine, Rochester, Minnesota

3 Pulmonary and Critical Care and Sleep Division, University of California, San Diego

\section{Address correspondence to:}

Xavier Soler, MD, PhD

Pulmonary and Critical Care and Sleep Division,

University of California,

San Diego, California

Phone: (619)543-7333

Email: xsoler@ucsd.edu

\section{Keywords:}

exercise; COPD; actigraphy; activity monitors; 6- minute walk; shuttle test; questionnaire; pedometer; accelerometer; activities of daily life; lung

\section{Introduction}

The detrimental consequences of the sedentary lifestyle in patients with COPD have substantially increased interest in physical activity (PA) monitoring research in the past decade. The World Health Organization (WHO) defines PA as "any bodily movement produced by skeletal muscles that require energy expenditure." Progressive dyspnea in patients with COPD causes a spiral of deconditioning due to persistent inactivity and, therefore, to even more activity limitation. ${ }^{1-6}$ Reduced PA levels in COPD has been associated with increased morbidity and mortality as well as sustained disability, depression, and social and physical isolation. ${ }^{7-9}$ Depression, a common comorbid condition 
in COPD, may also negatively contribute to physical inactivity and difficult lifestyle changes in these patients. Current COPD treatment guidelines strongly recommend pulmonary rehabilitation (PR) programs, with exercise being an essential component in PR. ${ }^{10}$ Although the intent is to increase PA after the PR program, the translation to daily $\mathrm{PA}$ is questioned as it is not routinely measured. ${ }^{10,11}$ Because of the inherent difficulties for patients to maintain regular PA and the learned lifestyle changes over time after pulmonary rehabilitation, several tools have been developed to quantify PA in patients with limited exercise capacity, such as with COPD patients. Compared to their use in normal or high functioning individuals (e.g. athletes), use of activity monitors can be less accurate in many patients with moderate to severe COPD, whose walking speeds can be as low as 0.5 miles per hour. Due to the advances in technology, new PA devices may be able to provide sufficiently accurate measurements in such patients. However, this field is quite new, and some of these devices are still being evaluated in this particular group of patients. It is important to recognize that because of the live feedback provided by PA monitors, their use may be very appropriate in a clinical setting as they can encourage patients to maintain higher levels of exercise and ultimately lead to the intended positive behavior changes.

This review will focus on available instruments to measure PA in patients with chronic lung disease, specifically COPD. The reliability and validity of each method and potential clinical applications will also be discussed. Measuring PA accurately in such patients may help to improve patient behavior, mood, daily activity level, and health-related quality of life and, potentially, help reduce exacerbations and dyspnea.

\section{Methods}

We used PubMed and Web of Science engine platforms for a literature search in April 2014. The key words used were COPD and physical activity with the terms, questionnaire, pedometer, accelerometer, activity monitoring, and activities of daily life. We then reviewed the references identified in order to refine our search. Each article was inspected manually. We limited selection to those studies that: (1) included COPD patients as the study population, (2) were in adults, and (3) measured PA levels. Additional tools that assess functional status, self-efficacy, health-related quality- of-life, and functional exercise capacity are beyond the scope of this review and were, therefore, excluded.

\section{Physical Activity Measurement}

\section{Self-reports}

\section{Overview}

Self-reports are subjective methods to collect PA data and include questionnaires, activity diaries, and recall interviews. The typical measures in selfreports are intensity, frequency, duration, and type of PA. There are many questionnaires to assess PA such as Baecke's Physical Activity Questionnaire, Follick's Diary, the Minnesota Leisure Time Physical Activity Questionnaire, the Physical Activity Scale for the Elderly (PASE), the Zutphen Physical Activity questionnaires (ZPAQ), the Stanford Usual Activity Questionnaire, the Stanford Brief Activity Scale, the Stanford 7-day Physical Activity Recall (PAR) scale, the Paffenbarger Physical Activity Questionnaire, the Saltin and Grimby Questionnaire, and the Yale Physical Activity Survey (Table 1). The characteristics and use of these questionnaires have been widely discussed elsewhere. ${ }^{12,13}$

\section{Reliability and Validity in COPD Patients}

Test-retest reliability refers to the degree that an instrument produces consistent results when administrated multiple times in the same individuals. Although some studies evaluated the reliability of questionnaires used to quantify PA in healthy individuals, none were specific to patients with COPD. ${ }^{2}$ Criterion validity refers to the degree that an instrument can predict the test result measured by an objective reference method. Many validation studies of PA questionnaires were performed in the elderly or general population and not in COPD. ${ }^{13,14}$ Because of the common inactivity and low exercise capacity associated with COPD, caution is warranted in applying these instruments to this population.

Fortunately, a number of studies validating the questionnaires have been published recently. Most studies compare a subjective measure (e.g., questionnaire) with an objective one (e.g., activity monitor) such as with an accelerometer. In a study of 172 COPD patients in Spain, Donaire-Gonzalez et al suggested that the Yale Physical Activity Survey might be a useful tool to classify physical activity in 


\section{Table 1. Overview of the Questionnaires Commonly Used in COPD Studies}

Name

Advantages

Limitations

Applicability

Baecke's Physical Activity

Questionnaire

\begin{abstract}
Brief. Good for the elderly
\end{abstract}
No validation study in COPD

Clinical

Follick's diary

Less recall bias

Validated in COPD patients

Involving only certain

movements

Research

Activity on leisure time only Research

Minnesota Leisure Time Physical Modified for COPD patients

Activity Questionnaire

Physical Activity Scale for the

Elderly

Good predictor of severe physical inactivity ${ }^{17}$

Not suitable for young population

Zutphen Physical Activity

Questionnaire

Brief. Self-administered

Stanford Seven-day Physical

Activity Recall

Useful to stratify COPD

patients ${ }^{18}$

Yale Physical Activity Survey

Validated in COPD $^{15}$

Validated in different countries

Not accurate in very inactive population 16

Clinical

Require 7 days recall

Clinical

Research

Administrated by interview

Research

International Physical Activity

Questionnaire

QUANTAP $^{a}$ system

Lifetime measurement

year-old adults ${ }^{19}$

COPDEX Questionnaire ${ }^{b}$

Designed for COPD

New. Needs more validation studies

International studies

${ }^{\mathrm{a}}$ Quantification de l'Activité Physique system; bCOPD Exercise Study Questionnaire
Longitudinal studies

Research this population. ${ }^{15}$ On the other hand, van Gestel et al concluded that the ZPAQ questionnaire could not be used to categorize activity accurately in an extremely inactive population (common among patients with COPD). ${ }^{16}$ In a recent study of 165 COPD patients, DePew et al demonstrated that the PASE scale was a good predictor of severe physical inactivity. ${ }^{17}$ A UK study in 43 COPD patients assessed the validity of different activity measurement questionnaires that included the Stanford PAR, the Baecke, the PASE, and the Zutphen. The questionaires were compared against the SenseWear armband which patients wore for 7 days. The authors concluded that only the Stanford PAR questionnaire distinguished between highly functional and inactive COPD participants and may be a useful tool to stratify COPD patients according to their level of physical activity. ${ }^{18}$

\section{Novel Questionnaires Used for PA Measurement in COPD}

The International Physical Activity Questionnaire (IPAQ) can categorize PA levels as low, moderate, or high, or provide a continuous activity measurement. In one study, the test-retest reliability of IPAQ was found to be acceptable to excellent (Spearman's rho clustered around 0.8) and the criterion validity of IPAQ showed a moderate correlation ( $\mathrm{rho}=0.3$ ). It was, therefore, considered to be a reasonable measurement of PA among 18 to 65 year-old adults. ${ }^{19}$ Although many patients with COPD are 70 years of age or older, many are younger and therefore, IPAQ can be considered as a reasonable measurement of PA. A Chilean study found the PA measured by IPAQ to be decreased early in the progression of COPD when dyspnea was still mild. ${ }^{20}$

The Quantification de l'Activité Physique (QUANTAP) system uses computer-assisted software to 
assess PA over a lifetime in 4 areas: 1 ) sports at school, 2) leisure sports, 3) occupation, and 4) daily activities. The information includes the type of PA, duration, and frequency in each area. The reliability and validity of the questionnaire was assessed in the elderly population. ${ }^{21}$ Gouzi et al demonstrated that COPD patients reduced their PA sooner than sedentary healthy individuals. ${ }^{22}$

The COPD Exercise Study Questionnaire (COPDEX Questionnaire) asks participants about their exercise routine and other daily activities to assess the PA level. ${ }^{23}$ The results of the Exercise Study showed that when the severity of disease progressed the individuals became less active. However, we are not aware of any published validation study of the COPDEX Questionnaire.

\section{Motion Detectors}

\section{Overview}

Pedometers and accelerometers are motion sensors commonly used for objective PA activity measurement in both clinical and research settings. Pedometers are step counter devices worn on the waist and designed to measure vertical movement. Accelerometers are motion sensor instruments that measure body movement (acceleration); they can detect movement in 1 (uniaxial) or multiple (multiaxial) planes (e.g., 2 planes such as vertical and mediolateral direction or 3 planes such as vertical, mediolateral, and anterior-posterior directions). The triaxial devices seem to be more accurate in measuring PA. ${ }^{24}$

Accelerometers are more advanced technically and more expensive than pedometers. Therefore, price may be an important factor affecting which device to use for research or clinical needs. Vertical motion assessment by an accelerometer can be considered equivalent to a pedometer. Accelerometers can be worn on the wrist, waist, or ankle. They typically measure and store the quantity and intensity of movements over a period of time. A mathematical algorithm converts the intensity, frequency and duration of bodily motion into a numerical value called vector magnitude unit (VMU), the vectorial sum of movements (activity counts) in 3 orthogonal directions. The output is an estimate of energy expenditure (EE).

\section{Pedometers}

A variety of pedometer models have been marketed. Some major producers include Omron (Lake Forest, Illinois), Yamax Digi-Walker (Tokyo, Japan), Accusplit
(Livermore, CA), FreeStyle (Long Island, NY), NewLifestyles (Lees Summit, MO), Oregon Scientific (Cannon Beach, OR), Sportline (Yonkers, NY), and Walk4Life (Plainfields, IL). An overview of the motion detectors commonly used is provided in Table 2 . Testretest reliability of pedometers is generally high (e.g., intraclass correlation coefficient of 0.94); however, variations between devices of the same model have been noted, so they should be used with caution. ${ }^{25}$ One study found that results from pedometers were highly correlated with triaxial accelerometers; ${ }^{26}$ however, they tend to have lower accuracy and generally underestimate activity in individuals with very slow walking or inactivity, a hallmark of COPD patients. ${ }^{27} \mathrm{~A}$ validation study of the DigiWalker SW701 device found that it was accurate for step counting and EE estimation in COPD patients at faster walking speeds, but significantly underestimated activity at slower speeds. ${ }^{28}$ Another study in 36 COPD patients assessed the criterion validity of the DigiWalker SW701 against indirect calorimetry and reported significant underestimation in the sum and for each of 5 activities (walking on the level, walking on the level carrying a backpack, walking up/ downstairs, rising/sitting in chairs and moving objects in and out of a shelf). ${ }^{29}$ One study of the accuracy of the Omron HJ720ITC in 51 COPD patients found that the pedometer was accurate at a regular walking speed $>0.94 \mathrm{~m} / \mathrm{s}$ but had higher variability at lower levels of exercise.

\section{Accelerometers}

Accelerometers are more sophisticated motion sensors compared to pedometers. Many accelerometers have been developed, such as the Computer Science Applications (CSA) activity monitor (Shalimar, Florida), TriTrac-R3D (Professional Products, Madison, Wisconsin), RT3 Triaxial Research Tracker (RT3) (Stayhealthy, Monrovia, California), BioTrainer-Pro (IM Systems, Baltimore, Maryland), SenseWear Armband (BodyMedia Inc, Pittsburgh, Pennsylvania), DynaPort Activity Monitor, MiniMod, Move Monitor, and ADLmonitor (McRoberts BV, the Hague, the Netherlands), Actiwatch Spectrum and Uniaxial Accelerometer (Pensacola, FL), Lifecorder PLUS (Kenz Suzuken Co Ltd, Nagoya, Japan), and Actigraph GT3X (Actigraph LLC, Pensacola, FL). Reliability and validity of accelerometers are generally high, as noted in previous reviews. ${ }^{13,14}$ Recently, new accelerometers with improved technology have been developed and shown to have greater reliability 


\section{Table 2. Overview of the Motion Detectors Commonly Used in COPD studies}

\begin{tabular}{|c|c|c|c|c|c|c|c|}
\hline Name & Manufacture & Type & Locations & Outcomes & Advantages & Limitation & Applicability \\
\hline $\begin{array}{l}\text { DigiWalker } \\
\text { SW-701 }\end{array}$ & $\begin{array}{c}\text { Yamax } \\
\text { Tokyo, Japan }\end{array}$ & Ped & Hip & Steps & $\begin{array}{l}\text { Good for fast } \\
\text { walk }^{28}\end{array}$ & $\begin{array}{l}\text { Underestimated } \\
\text { in certain } \\
\text { activities }^{28,29}\end{array}$ & $\begin{array}{l}\text { Individual } \\
\text { use } \\
\text { Large studies }\end{array}$ \\
\hline $\begin{array}{l}\text { Omron } \\
\text { HJ720ITC }\end{array}$ & $\begin{array}{l}\text { Omron } \\
\text { Lake Forest, } \\
\text { Illinois }\end{array}$ & Ped & Hip & Steps & $\begin{array}{l}\text { Accurate at a } \\
\text { regular walking } \\
\text { speed }\end{array}$ & $\begin{array}{l}\text { Higher variability } \\
\text { at lower levels } \\
\text { of exercise }\end{array}$ & $\begin{array}{c}\text { Individual } \\
\text { use } \\
\text { Large studies }\end{array}$ \\
\hline Fitbit & $\begin{array}{c}\text { Fitbit Inc } \\
\text { San Francisco, } \\
\text { CA }\end{array}$ & Ped & Waist & Steps & $\begin{array}{l}\text { Simplicity and } \\
\text { low cost }\end{array}$ & $\begin{array}{c}\text { Underestimate } \\
\qquad \mathrm{EE}^{43}\end{array}$ & $\begin{array}{l}\text { Individual } \\
\text { use }\end{array}$ \\
\hline $\begin{array}{l}\text { Power-Walker } \\
610\end{array}$ & $\begin{array}{c}\text { Yamax } \\
\text { Tokyo, Japan }\end{array}$ & $\begin{array}{l}\text { Ped } \\
\text { Tri }\end{array}$ & Waist & $\begin{array}{l}\text { Steps } \\
\text { distance } \\
\text { time }\end{array}$ & $\begin{array}{l}\text { Reliable and valid } \\
\text { for step counts }\end{array}$ & $\begin{array}{l}\text { Not good for } \\
\text { EE during } \\
\text { slow walking }\end{array}$ & $\begin{array}{l}\text { Higher } \\
\text { accuracy } \\
\text { studies }\end{array}$ \\
\hline $\begin{array}{l}\text { Lifecorder } \\
\text { PLUS }\end{array}$ & $\begin{array}{l}\text { Kenz Suzuken } \\
\text { Nagoya, Japan }\end{array}$ & Uni & Waist & Steps & $\begin{array}{l}\text { Longer data } \\
\text { storage and } \\
\text { low cost }\end{array}$ & $\begin{array}{l}\text { One plane } \\
\text { measurement }\end{array}$ & $\begin{array}{l}\text { Individual } \\
\text { use } \\
\text { Large studies }\end{array}$ \\
\hline $\begin{array}{l}\text { Actiwatch } \\
\text { Spectrum }\end{array}$ & $\begin{array}{c}\text { Philips } \\
\text { Respironics } \\
\text { Bend, OR }\end{array}$ & Uni & Wrist & $\begin{array}{l}\text { Activity } \\
\text { counts }\end{array}$ & Lightweight & $\begin{array}{l}\text { One plane } \\
\text { measurement }\end{array}$ & $\begin{array}{c}\text { Individual } \\
\text { use } \\
\text { Large studies }\end{array}$ \\
\hline
\end{tabular}

\section{Triaxial Accelerometers and Multiple Sensors}

\begin{tabular}{|c|c|c|c|c|c|c|c|}
\hline $\begin{array}{l}\text { DynaPort } \\
\text { MiniMod }\end{array}$ & $\begin{array}{l}\text { McRoberts BV } \\
\text { the Hague, } \\
\text { Netherlands }\end{array}$ & Tri & Waist & $\begin{array}{l}\text { Intensity } \\
\text { Position } \\
\text { Steps }\end{array}$ & $\begin{array}{c}\text { High validity }{ }^{30,33} \\
\text { Discriminating between } \\
\text { walking speeds }{ }^{30} \\
\text { Accurately measure steps }{ }^{33}\end{array}$ & Expensive & $\begin{array}{l}\text { Higher } \\
\text { accuracy } \\
\text { studies }\end{array}$ \\
\hline $\begin{array}{l}\text { Actigraph } \\
\text { GT3X }\end{array}$ & $\begin{array}{l}\text { Actigraph LLC } \\
\text { Pensacola, FL }\end{array}$ & Tri & $\begin{array}{l}\text { Hip } \\
\text { Ankle } \\
\text { Waist }\end{array}$ & $\begin{array}{l}\text { VMU } \\
\text { steps }\end{array}$ & $\begin{array}{l}\text { High validity }{ }^{30} \\
\text { Discriminating between } \\
\text { walking speeds } \\
\text { Correlated with } \mathrm{EE}^{31}\end{array}$ & Expensive & $\begin{array}{l}\text { Higher } \\
\text { accuracy } \\
\text { studies }\end{array}$ \\
\hline $\begin{array}{l}\text { DynaPort } \\
\text { MoveMonitor }\end{array}$ & $\begin{array}{l}\text { McRoberts BV } \\
\text { the Hague, } \\
\text { Netherlands }\end{array}$ & Tri & Waist & $\begin{array}{l}\text { Intensity } \\
\text { Position } \\
\text { Steps }\end{array}$ & Correlated with $\mathrm{EE}^{31}$ & Expensive & $\begin{array}{l}\text { Higher } \\
\text { accuracy } \\
\text { studies }\end{array}$ \\
\hline $\begin{array}{l}\text { Triaxial Research } \\
\text { Tracker (RT3) }\end{array}$ & $\begin{array}{l}\text { StayHealthy Inc. } \\
\text { Monrovia, CA }\end{array}$ & Tri & $\begin{array}{l}\text { Hip } \\
\text { Waist }\end{array}$ & $\begin{array}{l}\text { VMU } \\
\text { activity } \\
\text { counts }\end{array}$ & Low cost & $\begin{array}{l}\text { Short data } \\
\text { storage }\end{array}$ & $\begin{array}{l}\text { Large } \\
\text { studies }\end{array}$ \\
\hline Actimarker & $\begin{array}{c}\text { Panasonic } \\
\text { Osaka, Japan }\end{array}$ & Tri & Waist & VMU & $\begin{array}{c}\text { Monitor PA > } 1 \\
\text { month Lightweight }\end{array}$ & Expensive & $\begin{array}{l}\text { Longitudinal } \\
\text { studies }\end{array}$ \\
\hline $\begin{array}{l}\text { SenseWear } \\
\text { Armband }\end{array}$ & $\begin{array}{l}\text { Bodymedia Inc. } \\
\text { Pittsburgh, PA }\end{array}$ & Multi & Arm & $\begin{array}{c}\text { Steps } \\
\text { movement } \\
\text { intensity }\end{array}$ & High validity ${ }^{30,33}$ & Expensive & Research \\
\hline $\begin{array}{l}\text { StepWatch } \\
\text { Activity Monitor } \\
\text { (SAM) }\end{array}$ & $\begin{array}{l}\text { Orthocare } \\
\text { Innovations } \\
\text { Seattle, WA }\end{array}$ & Multi & Ankle & Steps & $\begin{array}{l}\text { High accuracy } \\
\text { Detect steps at } \\
\text { slower speeds }\end{array}$ & Expensive & $\begin{array}{l}\text { Research } \\
\text { for the } \\
\text { elderly }\end{array}$ \\
\hline
\end{tabular}

EE: energy expenditure; VMU: vector magnitude units; Tri: Triaxial accelerometer; Multi: multisensor 
and validity. A few studies have validated these new accelerometers in COPD patients. For instance, Van Remoortel et al studied 6 activity monitors compared to indirect calorimetry as an objective method (gold standard) in 39 COPD patients and concluded that the DynaPort MiniMod, Actigraph GT3X, and SenseWear Armband had the highest validity, while the DynaPort MiniMod and Actigraph GT3X were also good at discriminating between different walking speeds. ${ }^{30}$ Another more recent validation study in $80 \mathrm{COPD}$ patients of 6 devices vs. indirect calorimety measured by doubly-labeled water included 2 uniaxial monitors (Lifecorder PLUS [Kenz Suzuken Co Ltd, Nagoya, Japan] and Actiwatch Spectrum [Philips Respironics, Bend, OR]), 3 triaxial monitors (Actigraph GT3X [Actigraph LLC, Pensacola, FL], DynaPort MoveMonitor [McRoberts BV, the Hague, the Netherlands] and RT3 [StayHealthy Inc., Monrovia, CA] ) and one multisensor monitor, a triaxial accelerometer with different sensors (SenseWear Armband; Bodymedia Inc., Pittsburgh, PA). Results showed the Actigraph GT3X and DynaPort MoveMonitor best explained the majority of the total EE variance not explained by total body water and were significantly correlated with activityEE. ${ }^{31}$ Cohen etalalso demonstrated that an accelerometer could accurately measure the walking and non-acceleration speeds with thresholds of $0.7 \mathrm{mph}$ and $0.25 \mathrm{mph}$, respectively. Such discriminatory power may be sufficient to capture many of the low-functioning patients with severe COPD. ${ }^{32}$ In another study, the SenseWear and the Minimod were validated against manual step counting, video analysis, and indirect calorimetry. ${ }^{33}$ The authors concluded that the Minimod could detect postures, walking, and steps accurately, while the step counts of SenseWear were not accurate and did not provide information on time spent in different postures and walking. In another validation study of SenseWear in 26 COPD patients the EE measured by SenseWear was fairly well related to the EE measured by indirect calorimetry and had good reliability. ${ }^{34}$ A most recent validation study comparing the accuracy of the DynaPort ADL-monitor, the DynaPort MiniMod monitor, and the SenseWear Armband with video recording showed that the MiniMod monitor had the smallest mean difference between step counts from monitors compared to manual step counts by video recording. ${ }^{35}$

\section{New Motion Sensors Used for PA Measurement in COPD}

The Power-Walker 610 (Yamax, Tokyo, Japan) is a pedometer combined with a triaxial accelerometer. The output includes step counting, EE estimation, walking distance, activity time, and walking intensity. A validation study in 30 COPD patients compared PowerWalker to a video recording for step counting, walking distance, activity time, and walking intensity and to the multisensor SenseWear Armband for EE estimation. The results indicated that the Power-Walker was reliable and highly valid for step counts during slow and fast walking and for EE during fast walking. Furthermore, during the performance of a circuit of activities of daily living, the device significantly underestimated activity time but provided an acceptable estimation of EE in a group basis. ${ }^{36}$ The StepWatch Activity Monitor (SAM) (Orthocare Innovations, Seattle, WA) is an accelerometer worn on the ankle that measures step counts from all walking. The step counts from SAM, validated against manual counts, proved to have an accuracy $>90 \%$ in $99 \%$ of $127 \mathrm{COPD}$ patients. ${ }^{37}$ Another study evaluating the accuracy and responsiveness of SAM in COPD patients demonstrated that SAM could detect steps in patients who walk very slowly with and without a rollator. ${ }^{38}$ Several other studies using SAM for PA measurement found that lower daily step counts measured by SAM predicted future acute exacerbations and COPD-related hospitalizations. ${ }^{39}$ A recent study found that combining an internet walking program with a pedometer can increase daily walking in COPD patients. ${ }^{40}$

A new triaxial accelerometer, Actimarker (Panasonic, Osaka, Japan), is a lightweight (36g) and small (74.5 $\times 13.4 \times 34.0 \mathrm{~mm}$ ) device worn at the waist that can continuously monitor PA for more than 1 month. A validation study demonstrated that Actimarker measurement was highly correlated with DynaPort and confirmed its reliability. ${ }^{41}$ Compared to DynaPort, Actimarker is more compact, lightweight, and has a longer lasting battery. Another newly developed pedometer, Fitbit (Fitbit Inc, San Francisco, CA), was evaluated in healthy adults, elderly, and persons with stroke and traumatic brain injury. ${ }^{42}$ A validation study of Fitbit by Takacs et al demonstrated that it provided valid measurements in healthy young adults. ${ }^{42}$ On the other hand, another study found that Fitbit significantly underestimated EE. ${ }^{43}$ More highly functioning, ambulatory patients, such as those with stroke or traumatic brain injury, may be particularly suited for 
using Fitbit. ${ }^{44}$ Similar results were found by Lauritizen et al in elderly individuals with normal mobility or otherwise healthy adults. ${ }^{45}$ Although this device hasn't been evaluated in the COPD population, it may play a role for individuals with higher exercise capacity because of its simplicity of use and low cost.

\section{Discussion}

In patients with COPD, the activity monitor devices can be important instruments to measure baseline exercise capacity and stability or progression over the course of the disease. They can also help with maintaining behavior changes because of the inherent live feedback. Current PA research in COPD patients has focused on 4 major topics: 1) how PA predicts functional status and quality of life in COPD patients; 2) how interventions such as PR, home exercising programs, or new available drugs improve $\mathrm{PA}_{;}^{46-50}$ 3) characterization of $\mathrm{PA}$ in patients with associated comorbidities (e.g. anxiety, exacerbations); ${ }^{46,49}$ and 4) the validity and reliability of the PA devices.

Self-report methods are inexpensive and relatively easy to administer but are less accurate than objective methods and are recommended for epidemiological studies or when direct activity monitoring is not feasible. Their reliability is typically good to excellent while their criterion validity is generally poor to moderate. ${ }^{51-53}$ These are flexible methods that can be administered by mail, web-based platforms, in-person visits, or via telephone. The major disadvantage is recall bias and an overestimation of PA levels, especially in low functioning individuals, ${ }^{3,12}$ and in those with cognitive impairment. ${ }^{54}$ In selecting a questionnaire for patients with COPD, we need to consider the type of measurement needed (e.g., categories [low, moderate, high] vs. continuous score). For example, the Baecke Physical Activity Questionnaire and the PASE estimate the PA level as a continuous measure while the IPAQ estimates the PA level as either continuous or in categories. If we need to evaluate a lifetime PA, the QUANTAP would be a reasonable choice.

Pedometers are simple to use, relatively inexpensive, and convenient with acceptable validity and reliability. However, they lack information about the pattern, time, and intensity of PA and compared to accelerometers, can only detect vertical movements and are not sensitive to more subtle movements seen at low walking speeds.

Accelerometers (especially multiaxial) can provide more detailed information but at a higher cost. In patients with low levels of activity such as those with COPD, advanced pulmonary fibrosis, pulmonary hypertension, or other severe chronic lung disorders, we may need a more accurate and sensitive device due to the common limited exercise capacity. The field of activity monitoring with accelerometers is frantically advancing and now more affordable monitors are being produced and may represent the future of the field.

The duration of testing required for meaningful data is at least 4 days. ${ }^{55}$ There is not much difference between pedometers and accelerometers regarding wear time or position. Usually, current recommendations for pedometers are to obtain measurements over 1 week to help reduce variation between weekday and weekends. $^{56-58}$ For accelerometers, it is generally recommended to obtain between 4 and 12 measurement days for more accurate data. ${ }^{58-61}$ Some authors have suggested 2 weeks of data collection, although to our knowledge this has not been demonstrated to be necessary.

In most of the current published COPD literature, accelerometers are used for PA measurement. In evaluating changes in lower extremity exercise tolerance following PR, pedometers have been found to be of limited use, while available questionnaires provide subjective measures of PA that are subject to substantial recall bias. ${ }^{62}$

Future PA monitoring studies should include the new and simple technology (Fitbit, Garmin Vivofit and Polar Loop). In addition, studies need to be able to properly evaluate upper body activity motion, which is an important component in COPD for activities of daily living. To date, studies have been mainly focused on whole body physical activities (using questionnaires or accelerometers) or lower body activities (using pedometer for step counts) because of the difficulty in assessing upper body motion. Therefore, we cannot assess the independent effect of upper body activities in such patients. Upper body exercise training has been included in PR specific to COPD patients. ${ }^{63-65}$ In addition, upper body exercise can be especially useful in wheelchair bound patients and in the elderly with high fall risks.

Furthermore, PA monitoring in patients with COPD is useful for both clinical and research purposes. In research as a tool to evaluate interventions such as $\mathrm{PR}$, home exercising programs, or the effects of new drugs under development. In a clinical setting, activity 
monitoring may be important to help guide selfmotivation strategies, evaluate mid to long outcomes, and provide live feedback that leads to desired patient behavior modification, which can be monitored using telemedicine resources and therefore have a true live patient-to-health provider interaction.

\section{Conclusion and Future Directions}

While many options are available to assess PA, the decision about which method to use for a particular purpose requires consideration of several factors, including: 1) the specific research question, 2) the population, 3) availability of a specific device, 4) principal investigator and staff training, and: 5) available budget (Table 3 ).

In general, self-assessment questionnaires are appropriate for large epidemiological studies because of the associated low cost and ease of administration. For smaller studies that require higher accuracy (e.g. drug-related studies or COPD outcomes after a PR program), accelerometers, and particularly the new technology offered, need to be further investigated and may be preferred. Pedometers can be used for individual self-assessment and biofeedback, and can provide personalized physical activity profiles to help behavior modification.

The new generations of devices to assess PA incorporate complementary technology like interphases with tablets and telephones and can be a significant reinforcement for behavior change as the patient is given direct feedback. There is a need for judgment of what device is appropriate in a case-bycase fashion, as elderly individuals may prefer simpler devices. Furthermore, the addition of physiologic measures (e.g. heart rate, pulse oximetry) or global positioning system- GPS capabilities may improve the characterization of daily activities in patients with COPD and help to tailor intervention strategies particularly in $\mathrm{PR}$ where improving daily physical activity is a much desired but not yet attained outcome.

\section{Table 3. Recommended Methods of Physical Activity Measurement}

Methods

Self-assessment questionnaire

QUANTAP $^{\text {a }}$ system Lifetime physical activity measurement

Epidemiological study or evaluation of self-

motivated exercise program

Studies involving drug regimens, or evaluation outcomes after pulmonary rehabilitation
Characteristics

Large number of participants

\section{Comment}

Low cost and easy to apply but less reliability or validity
Accelerometers

\section{Pedometers}

New technology
(e.g. Fitbit, Garmin
Vivofit and Polar
Loop)

Self-motivated exercise program
Focus on the lifetime longitudinal PA measurement

Large number of participants and low need of technical support

Smaller studies but higher accuracy is necessary
Computer-assisted software designed for the purpose

Moderate reliability and validity with lower cost.

Higher reliability and validity but higher cost
Lightweight, easy to wear, and good for daily use
Clinical trials and validation studies underway

\footnotetext{
a'Quantification de l'Activité Physique system
} 


\section{References}

1. Pauwels RA, Buist AS, Calverley PM, et al. Global strategy for the diagnosis, management, and prevention of chronic obstructive pulmonary disease. NHLBI/WHO Global Initiative for Chronic Obstructive Lung Disease (GOLD) Workshop summary. Am J Respir Crit Care Med. 2001;163(5):1256-1276. doi: http://dx.doi. org/10.1164/ajrccm.163.5.2101039

2. Pitta F, Troosters T, Probst VS, Spruit MA, Decramer M, Gosselink R. Physical activity and hospitalization for exacerbation of COPD. Chest. 2006;129(3):536-544. doi: http:// dx.doi.org/10.1378/chest.129.3.536

3. Pitta F, Troosters T, Spruit MA, Probst VS, Decramer M, Gosselink R. Characteristics of physical activities in daily life in chronic obstructive pulmonary disease. Am J Respir Crit Care Med. 2005;171(9):972-977. doi: http://dx.doi.org/10.1164/ rccm.200407-8550C

4. Serres I, Gautier V, Varray A, Préfaut C. Impaired skeletal muscle endurance related to physical inactivity and altered lung function in COPD patients. Chest.1998;113(4):900-905. doi: http://dx.doi.org/10.1378/chest.113.4.900

5. Steele BG, Holt L, Belza B, Lakshmiraryan S, Buchner DM. Quantitating physical activity in COPD using a triaxial accelerometer. Chest. 2000;117(5):1359-1367. doi: http://dx.doi. org/10.1378/chest.117.5.1359

6. Watz H, Waschki B, Meyer T, Magnusssen H. Physical activity in patients with COPD. Eur Respir J. 2009;33(2):262-272. doi: http://dx.doi.org/10.1183/09031936.00024608

7. Garcia-Aymerich J, Farrero E, Felez MA, Izquierdo J, Marrades RM, Anto JM. Risk factors of readmission to hospital for a COPD exacerbation: a prospective study. Thorax. 2003;58(2):100-105. doi: http://dx.doi.org/10.1136/thorax.58.2.100

8. Garcia-Aymerich J, Lange P, Benet M, Schnohr P, Anto JM. Regular physical activity reduces hospital admission and mortality in chronic obstructive pulmonary disease: a population based cohort study. Thorax. 2006;61(9):772-778. doi: http://dx.doi.org/10.1136/thx.2006.060145

9. Gimeno-Santos E, Frei A, Steurer-Stey C, et al. Determinants and outcomes of physical activity in patients with COPD: a systematic review. Thorax. 2014. Published online first February 20, 2014.

10. Spruit MA, Singh SJ, Garvey C, et al. An official American Thoracic Society/European Respiratory Society statement: key concepts and advances in pulmonary rehabilitation. Am J Respir Crit Care Med. 2013;188(8):e13-64. doi: http://dx.doi. org/10.1164/rccm.201309-1634ST

11. Sassi-Dambron DE, Eakin EG, Ries AL, Kaplan RM. Treatment of dyspnea in COPD. A controlled clinical trial of dyspnea management strategies. Chest.1995;107(3):724-729. doi: http:// dx.doi.org/10.1378/chest.107.3.724

12. Pitta F, Troosters T, Spruit MA, Decramer M, Gosselink R. Activity monitoring for assessment of physical activities in daily life in patients with chronic obstructive pulmonary disease. Arch Phys Med Rehabil. 2005;86(10):1979-1985. doi: http://dx.doi. org/10.1016/j.apmr.2005.04.016
13. Benzo R. Activity monitoring in chronic obstructive pulmonary disease. J Cardiopulm Rehabil Prev. 2009;29(6):341-347. doi: http://dx.doi.org/10.1097/HCR.0b013e3181be7a3c

14. Pitta F, Troosters T, Probst VS, Spruit MA, Decramer M, Gosselink R. Quantifying physical activity in daily life with questionnaires and motion sensors in COPD. Eur Respir J. 2006;27(5):1040-1055. doi: http://dx.doi.org/10.1183/09031936.06.00064105

15. Donaire-Gonzalez D, Gimeno-Santos E, Serra I, et al; en representación del PAC COPD Study Group. [Validation of the Yale Physical Activity Survey in chronic obstructive pulmonary disease patients].(article in Spanish) Arch Bronconeumol. 2011;47(11):552-560.

doi: http://dx.doi.org/10.1016/j.arbr.2011.07.004

16. van Gestel AJ, Clarenbach CF, Stowhas AC, et al. Predicting daily physical activity in patients with chronic obstructive pulmonary disease. PLoS One. 2012;7(11):e48081.

17. DePew ZS, Garofoli AC, Novotny PJ, Benzo RP. Screening for severe physical inactivity in chronic obstructive pulmonary disease: the value of simple measures and the validation of two physical activity questionnaires. Chron Respir Dis. 2012;10(1):1927. doi: http://dx.doi.org/10.1177/1479972312464243

18. Garfield BE, Canavan JL, Smith CJ, et al. Stanford Seven-Day Physical Activity Recall questionnaire in COPD. Eur Respir J. 2011;40(2):356-362. doi: http://dx.doi.org/10.1183/09031936.00113611

19. Craig CL, Marshall AL, Sjostrom M, et al. International physical activity questionnaire: 12-country reliability and validity. Med Sci Sports Exerc. 2003;35(8):1381-1395. doi: http://dx.doi. org/10.1249/01.MSS.0000078924.61453.FB

20. Parada A, Klaassen J, Lisboa C, Lisboa C, Saldias F, Mendoza L Diaz O.[Reduction of physical activity in patients with chronic obstructive pulmonary disease](article in Spanish). Rev Med Chil. 2012;139(12):1562-1572. doi: http://dx.doi.org/10.4067/S0034-98872011001200005

21. Vuillemin A, Guillemin F, Denis G, Huot J, Jeandel C. A computer-assisted assessment of lifetime physical activity: reliability and validity of the QUANTAP software. Rev Epidemiol Sante Publique. 2000;48(2):157-167.

22. Gouzi F, Prefaut C, Abdellaoui A, et al. Evidence of an early physical activity reduction in chronic obstructive pulmonary disease patients. Arch Phys Med Rehabil. 2011;92(10):1611-1617 e1612.

23. Katajisto M, Kupiainen H, Rantanen P, et al. Physical inactivity in COPD and increased patient perception of dyspnea. Int $J$ Chron Obstruct Pulmon Dis. 2012;7:743-755. doi: http://dx.doi. org/10.2147/COPD.S35497

24. Plasqui G, Joosen AM, Kester AD, Goris AHC, Westerterp KR. Measuring free-living energy expenditure and physical activity with triaxial accelerometry. Obes Res. 2005;13(8):1363-1369. doi:http://dx.doi.org/10.1038/oby.2005.165

25. Schönhofer B, Ardes P, Geibel M, Kohler D, Jones PW. Evaluation of a movement detector to measure daily activity in patients with chronic lung disease. Eur Respir J.1997;10(12):2814-2819. doi: http://dx.doi.org/10.1183/09031936.97.10122814 
26. Leenders N, Sherman WM, Nagaraja HN. Comparisons of four methods of estimating physical activity in adult women. Med Sci Sports Exerc. 2000;32(7):1320-1326. doi: http://dx.doi. org/10.1097/00005768-200007000-00021

27. Steele BG, Belza B, Cain K, Warm C, Coppersmith J, Howard J. Bodies in motion: monitoring daily activity and exercise with motion sensors in people with chronic pulmonary disease. $\mathrm{J}$ Rehabil Res Dev. 2003;40(5 Suppl 2):45-58.

28. Furlanetto KC, Bisca GW, Oldemberg N, et al. Step counting and energy expenditure estimation in patients with chronic obstructive pulmonary disease and healthy elderly: accuracy of 2 motion sensors. Arch Phys Med Rehabil. 2010;91(2):261-267. doi: http://dx.doi.org/10.1016/j.apmr.2009.10.024

29. Cavalheri V, Donaria L, Ferreira T, et al. Energy expenditure during daily activities as measured by two motion sensors in patients with COPD. Respir Med. 2011;105(6):922-929. doi: http://dx.doi.org/10.1016/j.rmed.2011.01.004

30. Van Remoortel H, Raste Y, Louvaris Z, et al; for PROactive Consortium. Validity of six activity monitors in chronic obstructive pulmonary disease: a comparison with indirect calorimetry. PLoS One. 2012;7(6):e39198. doi: http://dx.doi. org/10.1371/journal.pone.0039198

31. Rabinovich RA, Louvaris Z, Raste Y, et al. Validity of physical activity monitors during daily life in patients with COPD. Eur Respir J. 2013;42(5):1205-1215. doi: http://dx.doi. org/10.1183/09031936.00134312

32. Cohen MD, Cutaia M. A novel approach to measuring activity in chronic obstructive pulmonary disease: using 2 activity monitors to classify daily activity. J Cardiopulm Rehabil Prev. 2010;30(3):186-194. doi: http://dx.doi.org/10.1097/HCR.0b013e3181d0c191

33. Langer D, Gosselink R, Sena R, Burton C, DeCramer M, Troosters T. Validation of two activity monitors in patients with COPD. Thorax. 2009;64(7):641-642.

doi: http://dx.doi.org/10.1136/thx.2008.112102

34. Hill K, Dolmage TE, Woon L, Goldstein R, Brooks D. Measurement properties of the SenseWear armband in adults with chronic obstructive pulmonary disease. Thorax. 2010;65(6):486-491. doi: http://dx.doi.org/10.1136/thx.2009.128702

35. Andersson M, Janson C, Emtner M. Accuracy of three activity monitors in patients with chronic obstructive pulmonary disease: A comparison with video recordings. COPD. 2014.e-Pub ahead of print April 15, 2014.

36. Sant'Anna T, Escobar VC, Fontana AD, Camillo CA, Hernandes NA, Pitta F. Evaluation of a new motion sensor in patients with chronic obstructive pulmonary disease. Arch Phys Med Rehabil. 2012;93(12):2319-2325. doi: http://dx.doi.org/10.1016/j. apmr.2012.05.027

37. Moy ML, Danilack VA, Weston NA, Garshick E. Daily step counts in a US cohort with COPD. Respir Med. 2012;106(7):962969. doi: http://dx.doi.org/10.1016/j.rmed.2012.03.016

38. Fujisaki K, Fujita H, Matsumoto H, Kagi H. [Rapid and simultaneous determination method for analysis of minerals in infant formula using ICP-MS](article in Japanese). Shokuhin Eiseigaku Zasshi. 2011;52(6):336-339.

doi: http://dx.doi.org/10.3358/shokueishi.52.336
39. Moy ML, Teylan M, Weston NA, Gagnon DR, Garshick E. Daily step count predicts acute exacerbations in a US cohort with COPD. PLoS One. 2013;8(4):e60400. doi: http://dx.doi. org/10.1371/journal.pone.0060400

40. Moy ML, Weston NA, Wilson EJ, Hess ML, Richardson CR. A pilot study of an Internet walking program and pedometer in COPD. Respir Med. 2012;106(9):1342-1350. doi: http://dx.doi. org/10.1016/j.rmed.2012.06.013

41. Sugino A, Minakata Y, Kanda M, et al. Validation of a compact motion sensor for the measurement of physical activity in patients with chronic obstructive pulmonary disease. Respiration. 2011;83(4):300-307. doi: http://dx.doi.org/10.1159/000330046

42. Takacs J, Pollock CL, Guenther JR, Bahar M, Napier C, Hunt MA. Validation of the Fitbit One activity monitor device during treadmill walking. J Sci Med Sport. 2014; 17(5): 496-500. doi: http://dx.doi.org/10.1016/j.jsams.2013.10.241

43. Dannecker KL, Sazonova NA, Melanson EL, Sazonov ES, Browning RC. A comparison of energy expenditure estimation of several physical activity monitors. Med Sci Sports Exerc. 2013;45(11):2105-2112.

doi: http://dx.doi.org/10.1249/MSS.0b013e318299d2eb

44. Fulk GD, Combs SA, Danks KA, Nirider CD, Raja B, Reisman DS. Accuracy of 2 activity monitors in detecting steps in people with stroke and traumatic brain injury. Phys Ther. 2014;94(2):222-229. doi: http://dx.doi.org/10.2522/ptj.20120525

45. Lauritzen J, Munoz A, Luis Sevillano J, Civit A. The usefulness of activity trackers in elderly with reduced mobility: a case study. Stud Health Technol. 2013;192:759-762.

46. Borges RC, Carvalho CR. Physical activity in daily life in Brazilian COPD patients during and after exacerbation. COPD. 2012;9(6):596-602. doi: http://dx.doi.org/10.3109/15412555.2012.705364

47. Hataji O, Naito M, Ito K, Watanabe F, Gabazza EC, Taguchi O. Indacaterol improves daily physical activity in patients with chronic obstructive pulmonary disease. Int J Chron Obstruct Pulmon Dis. 2013;8:1-5.

48. Mador MJ, Patel AN, Nadler J.Effects of pulmonary rehabilitation on activity levels in patients with chronic obstructive pulmonary disease. J Cardiopulm Rehabil Prev. 2010;31(1):52-59. doi: http://dx.doi.org/10.1097/HCR.0b013e3181ebf2ef

49. Nguyen HQ, Fan VS, Herting J, et al. Patients with COPD with higher levels of anxiety are more physically active. Chest. 2013;144(1):145-151. doi: http://dx.doi.org/10.1378/chest.12-1873

50. Pomidori L, Contoli M, Mandolesi G, Cogo A. A simple method for home exercise training in patients with chronic obstructive pulmonary disease: one-year study. J Cardiopulm Rehabil Prev. 2011;32(1):53-57. doi: http://dx.doi.org/10.1097/ HCR.0b013e31823be0ce

51. Giantomaso T, Makowsky L, Ashworth NL, Sankaran R. The validity of patient and physician estimates of walking distance. Clin Rehabil. 2003;17(4):394-401. doi: http://dx.doi. org/10.1191/0269215503cr626oa 
52. Sanders SH. Automated versus self-monitoring of 'up-time' in chronic low-back pain patients: a comparative study. Pain. 1983;15(4):399-405. doi: http://dx.doi.org/10.1016/0304-3959(83)90075-1

53. Shephard RJ. Limits to the measurement of habitual physical activity by questionnaires. Br J Sports Med. 2003;37(3):197-206. doi: http://dx.doi.org/10.1136/bjsm.37.3.197

54. Antonelli Incalzi R, Marra C, Giordano A, et al. Cognitive impairment in chronic obstructive pulmonary disease--a neuropsychological and spect study. J Neurol. 2003;250(3):325332. doi: http://dx.doi.org/10.1007/s00415-003-1005-4

55. Berlin JE, Storti KL, Brach JS. Using activity monitors to measure physical activity in free-living conditions. Phys Ther. 2006;86(8):1137-1145.

56. Bassett DR, Jr., Ainsworth BE, Leggett SR, et al. Accuracy of five electronic pedometers for measuring distance walked. Med Sci Sports Exerc.1996;28(8):1071-1077. doi: http://dx.doi. org/10.1097/00005768-199608000-00019

57. Bassett DR, Jr., Cureton AL, Ainsworth BE. Measurement of daily walking distance-questionnaire versus pedometer. Med Sci Sports Exerc. 2000;32(5):1018-1023. doi: http://dx.doi. org/10.1097/00005768-200005000-00021

58. GretebeckRJ,MontoyeHJ.Variabilityofsomeobjectivemeasures of physical activity. Med Sci Sports Exerc.1992;24(10):1167-1172. doi: http://dx.doi.org/10.1249/00005768-199210000-00016

59. Coleman KJ, Epstein LH. Application of generalizability theory to measurement of activity in males who are not regularly active: a preliminary report. Res Q Exerc Sport. 1998;69(1):58-63. doi: http://dx.doi.org/10.1080/02701367.1998.10607667

60. Levin S, Jacobs DR, Jr., Ainsworth BE, Richardson MT, Leon AS. Intra-individual variation and estimates of usual physical activity. Ann Epidemiol.1999;9(8):481-488. doi: http://dx.doi. org/10.1016/S1047-2797(99)00022-8

61. Pols MA, Peeters PH, Kemper HC, Grobbee DE. Methodological aspects of physical activity assessment in epidemiological studies. Eur J Epidemiol.1998;14(1):63-70. doi: http://dx.doi. org/10.1023/A:1007427831179

62. Dallas MI, McCusker C, Haggerty MC, Rochester CL, ZuWallack $\mathrm{R}$ and Northeast Pulmonary Consortium. Using pedometers to monitor walking activity in outcome assessment for pulmonary rehabilitation. Chron Respir Dis. 2009;6(4):217-224.

63. Ries AL. The importance of exercise in pulmonary rehabilitation. Clin Chest Med. 1994;15(2):327-337.

64. Ries AL, Bauldoff GS, Carlin BW, et al. Pulmonary Rehabilitation: Joint ACCP/AACVPR Evidence-Based Clinical Practice Guidelines. Chest. 2007;131(5 Suppl):4S-42S. doi: http://dx.doi. org/10.1378/chest.06-2418

65. Singh VP, Jani H, John V, Singh P, Joseley T. Effects of upper body resistance training on pulmonary functions in sedentary male smokers. Lung India. 2011;28(3):169-173. doi: http://dx.doi. org/10.4103/0970-2113.83971 